\title{
Research Paper Enhanced proteasomal activity is essential for long term survival and recurrence of innately radiation resistant residual glioblastoma cells
}

\author{
Jacinth Rajendra' ${ }^{1,7}$, Keshava K. Datta ${ }^{2}$, Sheikh Burhan Ud Din Farooqee ${ }^{3,7}$, Rahul \\ Thorat $^{5}$, Kiran Kumar ${ }^{2}$, Nilesh Gardi ${ }^{4}$, Ekjot Kaur ${ }^{1,7}$, Jyothi Nair ${ }^{1,7}$, Sameer Salunkhe ${ }^{1,7}$, \\ Ketaki Patkar ${ }^{1}$, Sanket Desai ${ }^{4,7}$, Jayant Sastri Goda ${ }^{8}$, Aliasgar Moiyadi ${ }^{6}$, Amit Dutt ${ }^{4,7}$, \\ Prasanna Venkatramann $^{3,7}$, Harsha Gowda ${ }^{2}$ and Shilpee Dutt ${ }^{1,7}$ \\ ${ }^{1}$ Shilpee Dutt Laboratory, Tata Memorial Centre, Advanced Centre for Treatment, Research and Education in Cancer (ACTREC), \\ Kharghar, Navi Mumbai, India \\ ${ }^{2}$ Institute of Bioinformatics, International Technology Park, Bangalore, India \\ ${ }^{3}$ Advanced Centre for Treatment, Research and Education in Cancer (ACTREC), Tata Memorial Centre (TMC), Kharghar, Navi \\ Mumbai, India \\ ${ }^{4}$ Integrated Genomics Laboratory, Advanced Centre for Treatment, Research and Education in Cancer, Tata Memorial Centre, \\ Navi Mumbai, Maharashtra, India \\ ${ }^{5}$ Laboratory Animal Facility, Advanced Centre for Treatment, Research and Education in Cancer (ACTREC), Tata Memorial \\ Centre (TMC), Kharghar, Navi Mumbai, India \\ ${ }^{6}$ Department of neurosurgery Tata Memorial Centre, Advanced Centre for Treatment, Research and Education in Cancer, Navi \\ Mumbai, India \\ ${ }^{7}$ Homi Bhabha National Institute, Training School Complex, Anushakti Nagar, Mumbai, India \\ ${ }^{8}$ Department of Radiation Oncology, Tata Memorial Centre, Advanced Centre for Treatment, Research and Education in \\ Cancer, Navi Mumbai, India
}

Correspondence to: Shilpee Dutt, email: sdutt@actrec.gov.in

Keywords: glioblastoma; radio-resistant cells; recurrence; proteomic analysis; proteasomes

Received: August 28, $2017 \quad$ Accepted: April 25, $2018 \quad$ Published: June 12, 2018

Copyright: Rajendra et al. This is an open-access article distributed under the terms of the Creative Commons Attribution License 3.0 (CC BY 3.0), which permits unrestricted use, distribution, and reproduction in any medium, provided the original author and source are credited.

\section{ABSTRACT}

Therapy resistance and recurrence in Glioblastoma is due to the presence of residual radiation resistant cells. However, because of their inaccessibility from patient biopsies, the molecular mechanisms driving their survival remain unexplored. Residual Radiation Resistant ( $R R$ ) and Relapse ( $R$ ) cells were captured using cellular radiation resistant model generated from patient derived primary cultures and cell lines. ITRAQ based quantitative proteomics was performed to identify pathways unique to RR cells followed by in vitro and in vivo experiments showing their role in radio-resistance. 2720 proteins were identified across Parent ( $P$ ), $R R$ and $R$ population with 824 and 874 differential proteins in RR and R cells. Unsupervised clustering showed proteasome pathway as the most significantly deregulated pathway in RR cells. Concordantly, the RR cells displayed enhanced expression and activity of proteasome subunits, which triggered NFkB signalling. Pharmacological inhibition of proteasome activity led to impeded NFkB transcriptional activity, radio-sensitization of $R R$ cells in vitro, and significantly reduced capacity to form orthotopic tumours in vivo. We demonstrate that combination of proteasome inhibitor with radio-therapy abolish the inaccessible residual resistant cells thereby preventing GBM recurrence. Furthermore, we identified first proteomic signature of $\mathbf{R R}$ cells that can be exploited for GBM therapeutics. 


\section{INTRODUCTION}

Glioblastoma is the most common and lethal primary brain tumour. Despite the multimodal therapy, tumour recurrence is major challenge in glioblastoma with patient survival less than 6 months post recurrence [1-4]. Recurrence in GBM is attributed to a subpopulation of cells that survive initial therapies and cause tumour regrowth $[5,6]$. However, targeting residual resistant cells of glioma is challenging since they are invisible in MRIs post initial treatment and they are inaccessible from the patient biopsies for biological studies $[7,8]$. We have previously reported development of a cellular model of radiation resistance using primary cultures from patient samples, which recapitulate the clinical scenario of resistance and enable us to capture residual radiation resistant (RR) cells [9] and understand their molecular mechanism of survival.

Since proteins are the ultimate biological effectors of the cells, in this study we have analyzed the total proteome of residual resistant cells of glioma [10-13]. Till date majority of proteomics studies in glioblastoma have focused on identification of differential proteins amongst different GBM cell lines, patient samples or within the same tumour to investigate the heterogeneity of glioblastoma, mechanism of chemoresistance and identification of diagnostic biomarkers [14-26]. However, none of these studies could identify survival mechanism of innately resistant cells due to their unavailability. This is the first report to identify the proteomic signature of residual resistant and the relapse cells of glioblastoma from cellular model. Data revealed a unique proteomic signature of RR and $\mathrm{R}$ cells with utmost clustering of deregulated genes uniquely in the RR cells. Contrary to previous reports which have shown a decrease in proteasome activity in radio resistant cells [27, 28], our data reveals that innately radio resistant GBM cells harbour increased expression of proteasomal subunits, enhanced proteasome activity and increased levels of proteasome substrate $\mathrm{p}-\mathrm{NFkB}$ and concordant increase of NFkB target genes. We demonstrate pharmacological inhibition of proteasomal activity reduces $\mathrm{NFkB}$ transcriptional activity and radio sensitizes RR cells. Furthermore absence of proteasome activity in RR cells also significantly decreases their ability to form tumours in vivo. Together, our proteomics data has delineated proteasomal pathway as one of the plausible targetable mechanisms that significantly contribute to the survival of innate radiation residual cells via the NFkB signalling cascade.

\section{RESULTS}

\section{Capturing innate radiation resistant $(R R)$ and Relapse $(\mathrm{R})$ cells from in vitro radiation resistant model}

To capture and understand the survival mechanisms of residual resistant cells of GBM, that are diagnostically undetectable post treatment, we generated in vitro radiation resistant model derived from cell lines and patient samples [9] (Figure 1A). Using the same protocol, in this study first the glioblastoma cell lines (SF268 and U87MG) and two short term primary cultures of patient samples (PS1 and PS2) were subjected to their respective lethal dose of radiation (6.5 Gy, $8 \mathrm{~Gy}, 6 \mathrm{~Gy}, 6.5 \mathrm{~Gy}$ ) as determined previously using clonogenic assay [9]. Post treatment initially the cells proliferate, but after 4-5 days post treatment more than $90 \%$ cells died leaving behind a small population $(<10 \%)$ surviving cells. These cells are the innately radiation resistant residual cells (RR) which remain viable but non-proliferative for approximately 7-10 days and acquire Multinucleated Giant (MNGCs) phenotype. However, instead of undergoing mitotic catastrophe, RR cells resume growth to form the relapse $(\mathrm{R})$ population. Figure $1 \mathrm{~B}$ shows graphs for SF268 and PS1 growth pattern of RR cells. The parent $(P)$, innately radiation resistant $(R R)$ and relapse (R) cells obtained from SF268 were then subjected to quantitative proteomic analysis. The three populations obtained from U87MG, PS1 and PS2 were used for validation and functional studies.

\section{Quantitative proteomic analysis radio resistant $(\mathrm{RR})$ and relapse $(\mathrm{R})$ cells}

iTRAQ based quantitative proteomic analysis was performed on parent, RR and $\mathrm{R}$ cell population of SF268. Figure 1C illustrates the proteomics workflow. Equal amounts of protein from the Parent, RR and $\mathrm{R}$ populations was digested with trypsin and their tryptic peptides were labelled with 114, 115 and 116 isobaric reagents respectively for differential protein expression analysis. The iTRAQ-labelled peptide samples were pooled, fractionated and analyzed by LC-MS/MS. The data obtained was searched against National Centre for Biotechnology Information RefSeq database (version 52 40) using Protein Discoverer (version 1.4) using MASCOT and SEQUEST. Compared to parent cells 824 proteins were found to be differentially expressed in RR cells compared to parent cells out of which 393 proteins were up-regulated (fold change $>1.5$ ) and 431 proteins were downregulated (fold change $<0.7$ ) while 874 proteins were differentially expressed in relapse population of which 352 proteins were up-regulated $(>1.5)$ and 522 proteins were downregulated $(<0.7) .1,392$ proteins were differentially regulated in R vs. RR out of which 747 proteins were upregulated $(>1.5)$ and 645 were downregulated $(<0.7)$ in the $\mathrm{R}$ population (Figure 1D). iTRAQ data was validated by analysing the expression levels of HRAS, EGFR, YBX3 (Figure 2A). Relative peptide intensity values of the three proteins from mass spectrometry showed concurrent expression with the western blot data (Figure 2B). 


\section{Unsupervised clustering of proteomics data identifies protein clusters uniquely differential in each population}

Since a cell's phenotype is an outcome of a collective network of biological processes, it was hypothesized that proteins showing similar expression pattern will participate in similar biological processes. Therefore, we first identified the proteins showing coexpression, for which unique master differential gene list was compiled the at least one of the three binary comparison (RR Vs. P, R Vs. P, R Vs. RR) which comprise of 1773 genes. Unsupervised clustering was performed for these genes based on their respective relative protein abundance values as represented in a heat map. The expression pattern of each cluster is illustrated as a line plot (Figure 2C). Analysis segregated the data set into five clusters (C1-C5) out of which two major clusters, cluster 2 and cluster 3 represented proteins that were exclusively enriched with uniquely downregulated and upregulated proteins in the RR population, respectively. Cluster 2 represents 783 proteins and Cluster 3 represents 641 proteins. Clusters 1, 4 and 5 comprised of proteins that showed similar expression pattern in RR and $\mathrm{R}$ cells. 134 proteins were found to be downregulated in the RR and $R$ as compared to the parent cells (cluster 1). The expression of 165 proteins remains at a basal level in the $\mathrm{P}$ and $\mathrm{RR}$ population however their expression declines in the $\mathrm{R}$ cells (cluster 4) and 70 proteins show an escalation in expression in the RR and R as compared to the P cells (cluster 5). Since we were interested to know how the RR cells survive, we focused on the proteins classified in cluster 2 and cluster 3 which comprised of proteins uniquely downregulated and upregulated in the RR cells, respectively.
A

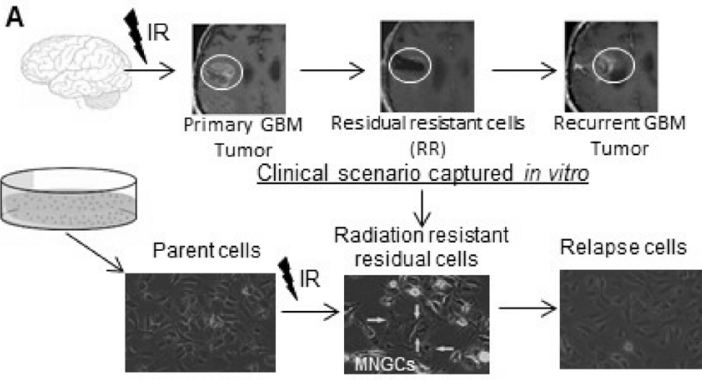

B
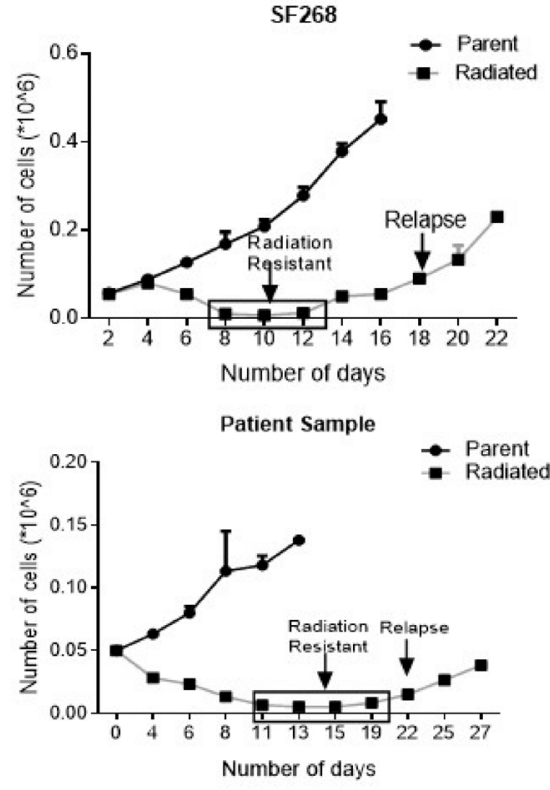

C

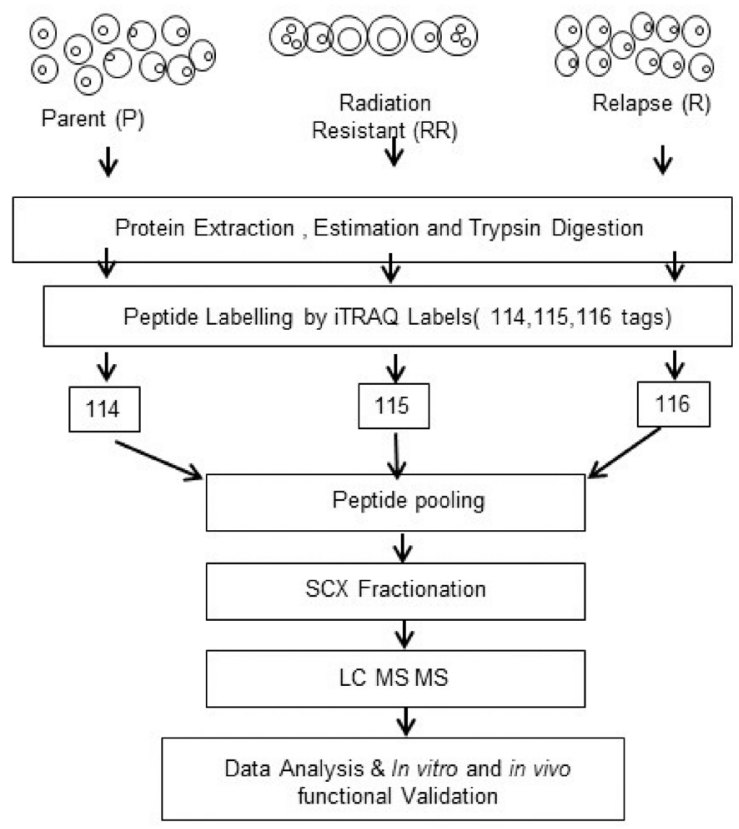

D

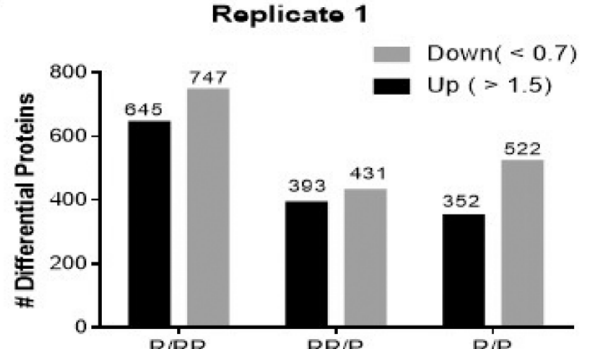

Figure 1: In vitro radiation resistant model. (A) The illustration depicts the clinical scenario in patient's pre and post treatment in which post-surgery there is a significant regression or complete abolishment of the tumor observed. However, in $>90 \%$ cases tumor recurs. This clinical scenario was recapitulated in an in vitro model. The images represent the SF268 Parent, innate Radiation Resistant (RR) enriched with multinucleated giant cells (MNGCs) and Relapse (R) population. (B) Graph represents the growth kinetics of SF268 and Patient Sample post lethal dose of radiation. (C) A schematic representation of the proteomics workflow. (D) Graphical representation of the number of differential proteins identified in the RR and R w.r.t P and R w.r.t RR by the proteomic analysis. Results in each bar graph are the composite data from three independent experiments performed in triplicate (mean $\pm \mathrm{SEM}$ ) 


\section{Pathway analysis reveals deregulation of proteasome and protein turnover machinery proteins in $R R$ population}

To analyze the molecular pathway that might be involved in the survival and radiation resistance mechanisms of RR cell, pathway enrichment analysis of the deregulated proteins in RR population compared to parent population in cluster 2 and cluster 3 was done using KEGG and REACTOME database (Figure 2D). In total 42 pathways were deregulated in cluster 2, 33 pathways were deregulated in cluster 3 . Interestingly, 11 pathways were commonly deregulated in both cluster 2 and 3 (Figure 2E). These pathways included glutathione metabolism, ribosome biogenesis in eukaryotes, RNA transport, spliceosome, and proteasome, protein processing in endoplasmic reticulum, regulation of actin cytoskeleton, non-alcoholic fatty liver disease (NAFLD), Alzheimer's disease, Huntington's disease and Epstein - Barr virus infection. Additionally, gene ontology and enrichment analysis of the entire differential proteins found in the RR compared to the parent cells, revealed 24 pathways enriched with upregulated (red circle) and downregulated proteins (green circle). Of these, 8 pathways were enriched with upregulated proteins and 16 pathways were enriched with downregulated proteins (Figure 3A). Out of the 8 pathways that were enriched with upregulated proteins, 5 statistically significant (Term $P$ value $<0.05$ ) pathways included Proteasome (8 proteins), Ubiquitin mediated proteolysis (10 proteins), Protein processing in Endoplasmic Reticulum (18 proteins), RNA Transport (17 proteins), oocyte meiosis (9 proteins). However, proteasome pathway was the most deregulated pathway based on the associated genes filter $(\mathrm{k} / \mathrm{K}$ ratio). Proteomic analysis from three biological replicates also revealed significant deregulation of proteasome pathway in the RR population (Supplementary Figure 2 and Figure 3B). The data sets of all the replicates have been deposited to the ProteomeXchangeConsortium (http://proteomecentral. proteomexchange.org) via the PRIDE partner repository. The internal ID of submission is: px-submission \#265394. A ProteomeXchange accession number will be generated after it has been loaded into the database. Proteasome subunits differential in all the four biological replicates have been represented in Table 1. Three subunits PSME1, PSMA7 and PSMB4 were used for validation by western blot (Figure 3C-3E).

\section{RR cells display enhanced proteasome activity and survival dependency on proteasome activity in vitro}

Since the RR population exhibited increased protein expression of proteasome subunits, we sought to observe if the expression correlated with proteasome activity. Therefore, proteasome activity was analysed in the parent and RR cells of SF268, U87MG, PS1 and PS2 using florigenic substrate Suc-LLVY-Amc. Indeed the RR population of SF268, U87MG, PS1 and PS2 showed $22.18 \%, 35.60 \%, 20.63 \%$ and $71.63 \%$ increase respectively in the proteasome activity compared to the parent cells (Figure 4A). Among the 9 subunits overexpressed in the RR, 3 subunits are part of the 19S regulatory subunit-PSMC1, PSMD2, PSMD7;3 subunits of the $20 \mathrm{~S}$ core particle-PSMA1, PSMA7, PSMB4 and 1 subunits of the $11 \mathrm{~S}$ regulatory subunits-PSME1. Most of the subunits belong to the classical proteasome. Hence the transcript levels of beta catalytic subunits: PSMB6 ( $\beta 1$ - caspase like activity), PSMB7 ( $\beta 2$-trypsin-like activity) and PSMB5 ( $\beta 5$-chymotrypsin-like activity), were checked. PSMB6 transcript levels were elevated in the RR population of all the samples, PSMB7 and PSMB5 were elevated in at least one cell line and one patient sample. Proteomics data also identified a regulatory subunit of immunoproteasome (PSME1). Therefore, the mRNA levels of its catalytic subunits PSMB9, PSMB8 and PSMB10 were also determined (Figure 4B). However, the transcript levels of the three subunits were not significantly high in any of the samples.

Since the RR population exhibited increased proteasome activity we wanted to analyze if the survival of RR cells was dependent on the proteasome activity. For this we used bortezomib (BTZ), a pharmacological inhibitor of proteasome routinely used in the treatment of multiple myeloma. First we determined the concentration of bortezomib at which proteasome activity was maximally inhibited with minimal cellular toxicity. For this proteasome activity of SF268 was assessed after 12 h. treatment of bortezomib at different concentrations $(0.01 \mathrm{nM}$ to $1000 \mathrm{nM})$. As seen from Figure 4C, $10 \mathrm{nM}$ of bortezomib was the minimum concentration at which significant inhibition of proteasome activity was observed and there was no significant cell death in RR as compared to parent. Once the non-toxic concentration of bortezomib on parent cells was determined, we wanted to see if the inhibition of proteasome sensitizes the glioma cells to radiation. SF268 and PS1 cells were treated for $12 \mathrm{hrs}$ with $10 \mathrm{nM}$ bortezomib and their \% cell survival was recorded at different doses of radiation. As shown in Figure 4D, bortezomib treatment significantly reduced the $\mathrm{D}_{0}$ dose of radiation from 5.07 Gy to 3.12 Gy and 4.4 Gy to 1.08 Gy for SF268 and PS1 respectively, showing that proteasome inhibition radio sensitizes glioma cells. We then wanted to analyse the effect of bortezomib on RR population that have higher proteasome activity. For this the parent and RR population of SF268 and U87 were treated with $0.1 \mathrm{nM}, 1 \mathrm{nM}$ and $10 \mathrm{nM}$ concentrations of bortezomib for $12 \mathrm{hrs}$. Following the treatment cells were monitored for proteasome activity. Both, parent and RR cells showed a gradual decrease in the activity of proteasomes with increasing concentration of the drug (Figure 5A and 5B). However, 72 hours post drug treatment RR cells were 
significantly (8\% SF268, 10\% U87 and 23\% PS1) more sensitive to proteasome inhibition compared to the parent population. PS2 showed similar \% reduction in viability as compared to the parent population at $10 \mathrm{nM}$ (Figure 5C).

\section{Proteasomes indirectly regulate RR cell survival via the $N F k B$ activation}

We further wanted to determine if the proteasome targets were down-regulated in the RR population due to degradation via ubiquitin mediated proteasome pathway. Down regulated proteins were analysed for presence of annotated ubiquitin binding lysine residues. These proteins were downloaded from Uniprot database [29] and parsed using in-house python scripts to determine presence of curated ubiquitin binding sites. Of the 431 proteins, 14 proteins were found to harbour lysine residues which can undergo ubiquitin modification (Supplementary Figure 1). One of the well-known substrates of the $26 \mathrm{~S}$ proteasome is I $\kappa$ B- $\alpha$ which upon degradation leads to the activation of the transcription factor NFkB. An increased proteasome activity should modulate the levels of activated NFkB in the RR population. Therefore, we checked for the levels of activated NFkB by western blot in the P and RR cells of cell lines and patient samples. Indeed, the RR cells displayed increased levels of activated NFkB in both the cell lines and PS1 (Figure 5D). Furthermore, the transcript levels of 9 NFkB target genes (TNF- $\alpha$, IL6, IkB-a, IFN- $\gamma$, ICAM1, COX2, NOD4, p16, SOD2) were screened in RR cells of the cell lines and patient sample by real-time PCR. A heat map representation of the 9 genes depicts upregulation of at least 6 genes out of the 9 in SF268, U87 and PS1 which also harbour increased expression of phosphoNFkB suggesting the presence of a transcriptionally active NFkB in RR cells (Figure 5E). To directly assess the NFkB transcriptional activity in the RR cells of U87, we monitored the relative promoter activity of the luciferase based NFkB reporter constructs in the P and RR cells. The
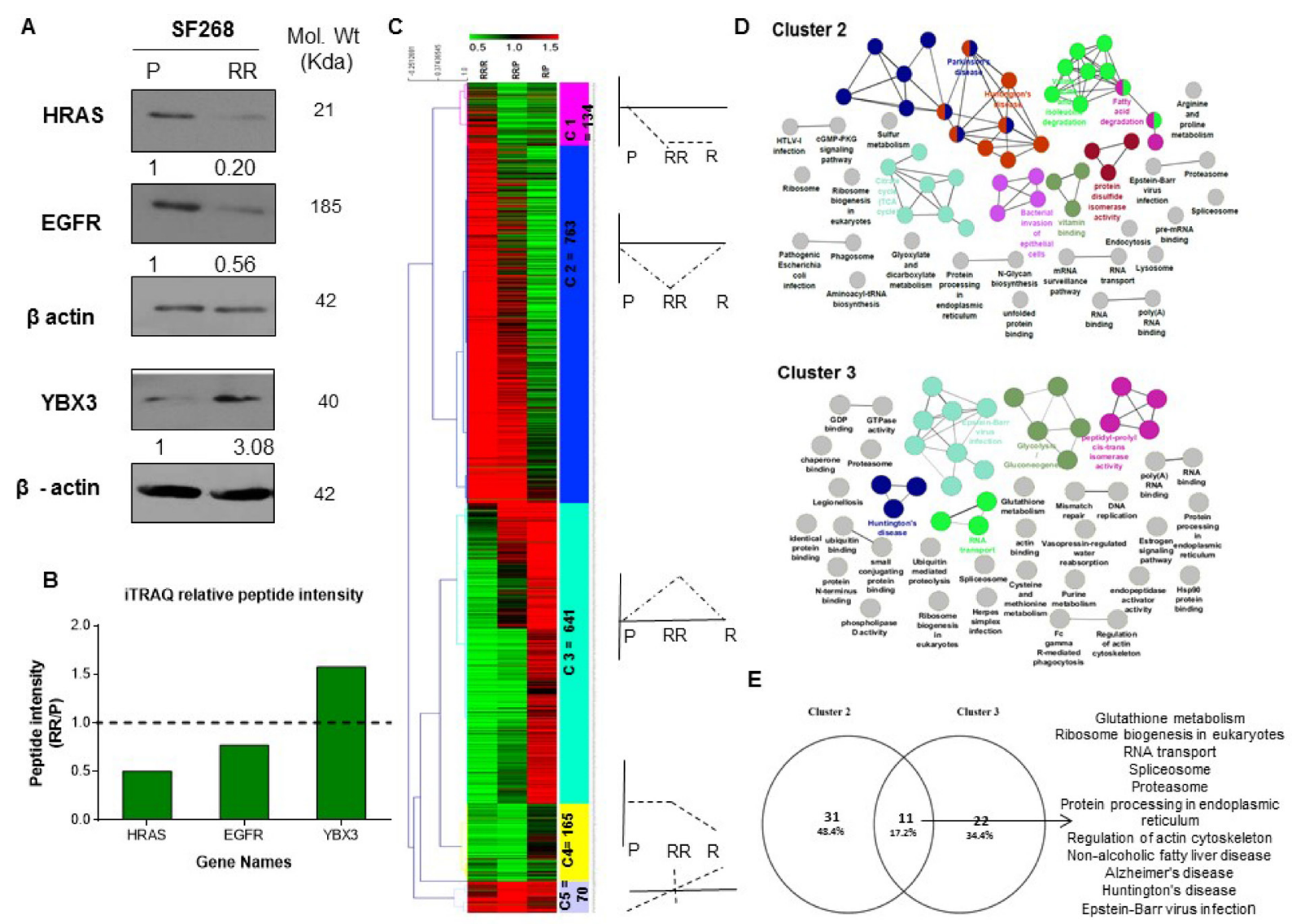

Figure 2: Proteomic analysis of the parent, radiation resistant and relapse population. (A) Western blots showing the expression of HRas, EGFR, YBX3 in Parent (P), Radiation Resistant (RR) and Relapse (R) population of SF268 cell line. $\beta$-actin was used as loading control. (B) Bar plot of the relative peptide intensity values of the mentioned proteins in RR/P and R/P as determined by iTRAQ. (C) Heat map representation of unsupervised hierarchical clustering of the proteins based on their relative peptide intensities in $\mathrm{R}$ w.r.t RR, RR w.r.t $P$ and R w.r.t P. Red- Up-regulation $>1.5$, Green- Down-regulation $<0.5$. Heat map is divided into clusters with a dotted plot representing the expression pattern of proteins in each cluster. (D) Pathway analysis of the Genes in cluster 2 and cluster were collapsed into pathways using ClueGo and CluePedia plugin of Cytoscape with KEGG and REACTOME pathway databases. Each coloured circle represents a pathway enriched with upregulated and downregulated protein in the RR cells but non-differential in the R cells. (E) Venn diagram for the overlap of pathways between cluster 2 and cluster 3 
RR cells showed a significant increase (20 fold) in NFkB transcriptional activity as compared to the parent population (P). Importantly, administration of the proteasome inhibitor (Bortezomib) in the $\mathrm{P}$ and RR cells diminished this activity by 1.5 and 3.0 fold demonstrating the dependency of NFkB activity on the proteasome activity. A synergistic inhibitory effect was observed in the presence of IkB-alpha construct and bortezomib in the P and RR cells. However, the RR cells displayed a much higher reduction as compared to the $\mathrm{P}$ cells (Figure 5F).

\section{Inhibition of proteasome activity inhibits tumour formation and in vivo}

We have shown that radiation resistant residual (RR) cells formed in our in vitro radiation resistant model systems retain their tumorigenic potential and re-grow to give rise to recurrent tumour. We first wanted to analyze if the RR cells are capable of forming tumour in vivo as well. For this pLenti6-luc2 U87MG cells [30] stably expressing luciferase were treated with the lethal dose of radiation 8 Gy and RR cells were collected. The parent and RR cells were then stereo tactically injected in the brain of 6-8 weeks old NOD/SCID mice. Tumour growth was monitored using bioluminescence imaging. As seen from Figure 6A left panel and Figure 6C, RR cells were able to give rise to tumours and had greater tumorigenic potential as compared to the parent cells.

We then evaluated the effect of proteasome inhibition on the tumorigenicity of the parent and RR cells. Since U87MG cells showed higher proteasome activity than the SF268 (Figure 4A), hence they also required a higher concentration of bortezomib $(50 \mathrm{nM})$ for reducing the viability of their RR. Therefore for in vivo studies U87MG parent and RR cells were treated with $50 \mathrm{nM}$ bortezomib for $12 \mathrm{hrs}$ prior to injection.

\section{A}

GO and Enrichment Analysis of the total differential proteins in RR w.r.t $P$

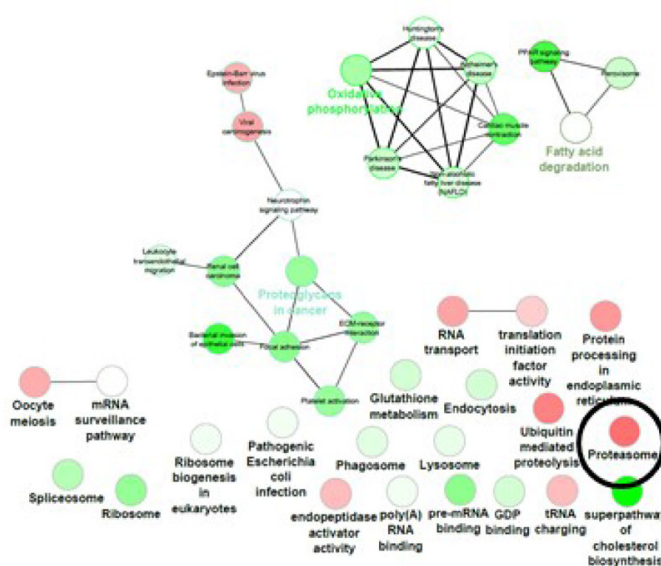

C

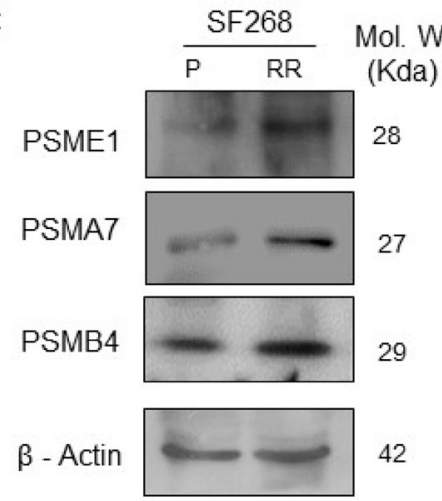

D

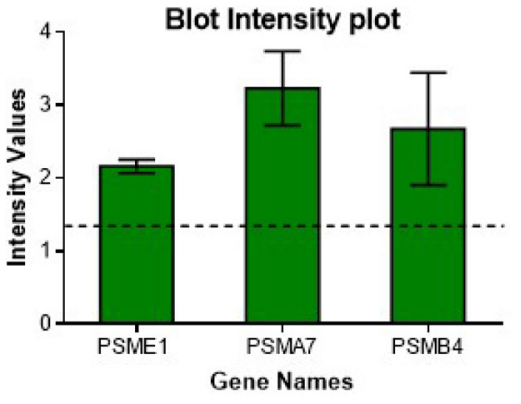

B

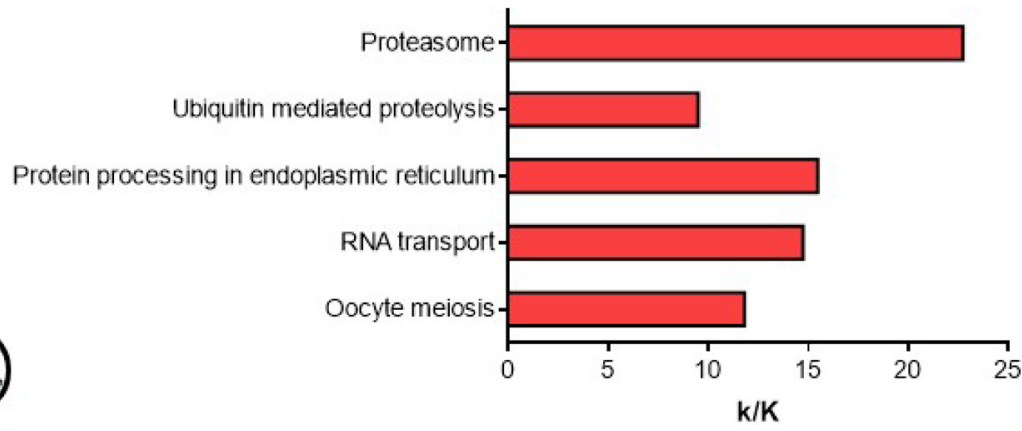

E

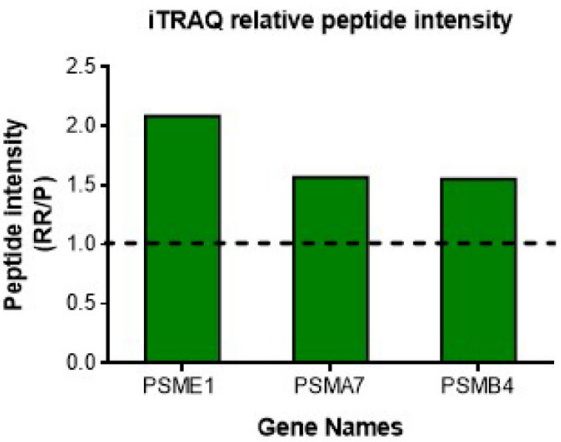

Figure 3: Deregulation of proteasome pathway in the radiation resistant population. (A) Pathway analysis of deregulated genes in Radiation Resistant (RR) vs. Parent (P) Genes deregulated in RR w.r.t P were collapsed into pathways using ClueGo and CluePedia plugin of Cytoscape with KEGG and REACTOME pathway databases. The colour gradient shows the number of genes of each group associated with the pathway. Equal proportions of the two clusters are represented in white. (B) KEGG pathways enriched with upregulated proteins according to their $\mathrm{k} / \mathrm{K}$ ratio. $\mathrm{k}-$ Number of genes identified from the pathway, $\mathrm{K}-$ Total number of genes curated in the KEGG database for a pathway. (C) Western blot showing the expression of PSME1, PSMA7 and PSMB4 parent (P), Radiation Resistant (RR) and Relapse (R) cells of SF268. $\beta$-actin was used as loading control. (D) Band intensity plot for the proteins validated by western blot using IMAGE J software. (E) Shows the relative peptide intensity values of the three proteins from iTRAQ analysis. 
Table 1: Represents the list of differential proteins identified in the proteasome pathway

\begin{tabular}{|c|c|c|c|c|}
\hline \multicolumn{5}{|c|}{ REPLICATE 1} \\
\hline $\begin{array}{l}\text { Gene } \\
\text { Symbol }\end{array}$ & Protein Description & $\begin{array}{c}\Sigma^{\#} \text { Unique } \\
\text { Peptides }\end{array}$ & $\begin{array}{c}\Sigma^{\#} \\
\text { PSMs }\end{array}$ & $\begin{array}{c}\text { Fold Change } \\
\text { in } R R / P\end{array}$ \\
\hline PSME1 & proteasome activator complex subunit 1 isoform 1 [Homo sapiens] & 4 & 4 & 2.085 \\
\hline PSMD7 & $26 \mathrm{~S}$ proteasome non-ATPase regulatory subunit 7 [Homo sapiens] & 3 & 6 & 1.977 \\
\hline PSMA1 & proteasome subunit alpha type- 1 isoform 3 [Homo sapiens] & 1 & 2 & 1.634 \\
\hline PSMD2 & $26 \mathrm{~S}$ proteasome non-ATPase regulatory subunit 2 [Homo sapiens] & 9 & 12 & 1.632 \\
\hline PSMA7 & proteasome subunit alpha type-7 [Homo sapiens] & 4 & 13 & 1.568 \\
\hline PSMB4 & proteasome subunit beta type-4 [Homo sapiens] & 2 & 4 & 1.550 \\
\hline PSMC1 & $26 \mathrm{~S}$ protease regulatory subunit 4 [Homo sapiens] & 6 & 10 & 1.518 \\
\hline PSMA3 & proteasome subunit alpha type-3 isoform 2 [Homo sapiens] & 2 & 4 & 0.656 \\
\hline PSMD14 & $26 \mathrm{~S}$ proteasome non-ATPase regulatory subunit 14 [Homo sapiens] & 3 & 4 & 0.593 \\
\hline \multicolumn{5}{|c|}{ REPLICATE 2} \\
\hline PSMD9 & $26 \mathrm{~S}$ proteasome non-ATPase regulatory subunit 9 isoform 1 & 4 & 6 & 1.88 \\
\hline PSMD10 & $26 \mathrm{~S}$ proteasome non-ATPase regulatory subunit 10 isoform 1 & 6 & 9 & 1.523 \\
\hline PSMC1 & $26 \mathrm{~S}$ protease regulatory subunit 4 & 19 & 57 & 1.381 \\
\hline PSMC6 & $26 \mathrm{~S}$ protease regulatory subunit $10 \mathrm{~B}$ & 16 & 48 & 1.356 \\
\hline PSMD8 & $26 \mathrm{~S}$ proteasome non-ATPase regulatory subunit 8 & 10 & 21 & 1.356 \\
\hline PSMA4 & proteasome subunit alpha type- 4 isoform 1 & 10 & 35 & 1.294 \\
\hline PSME2 & proteasome activator complex subunit 2 & 12 & 30 & 1.281 \\
\hline PSMD13 & $26 \mathrm{~S}$ proteasome non-ATPase regulatory subunit 13 isoform 1 & 19 & 47 & 1.243 \\
\hline PSMD7 & $26 \mathrm{~S}$ proteasome non-ATPase regulatory subunit 7 & 10 & 19 & 1.227 \\
\hline PSMD12 & $26 \mathrm{~S}$ proteasome non-ATPase regulatory subunit 12 isoform 1 & 22 & 44 & 1.207 \\
\hline \multicolumn{5}{|c|}{ REPLICATE 3} \\
\hline PSMD9 & $26 \mathrm{~S}$ proteasome non-ATPase regulatory subunit 9 isoform 1 & 5 & 7 & 3.587 \\
\hline PSMC5 & $26 \mathrm{~S}$ protease regulatory subunit 8 isoform 1 & 21 & 54 & 1.525 \\
\hline PSMB10 & proteasome subunit beta type- 10 precursor & 1 & 1 & 1.445 \\
\hline PSME2 & proteasome activator complex subunit 2 & 9 & 29 & 1.41 \\
\hline PSMD6 & $26 \mathrm{~S}$ proteasome non-ATPase regulatory subunit 6 isoform 2 & 19 & 30 & 1.382 \\
\hline PSMD4 & $26 \mathrm{~S}$ proteasome non-ATPase regulatory subunit 4 & 12 & 27 & 1.362 \\
\hline PSMA3 & proteasome subunit alpha type- 3 isoform 1 & 9 & 25 & 1.326 \\
\hline PSMD8 & $26 \mathrm{~S}$ proteasome non-ATPase regulatory subunit 8 & 9 & 19 & 1.321 \\
\hline PSMC6 & $26 \mathrm{~S}$ protease regulatory subunit $10 \mathrm{~B}$ & 18 & 52 & 1.318 \\
\hline PSMD13 & $26 \mathrm{~S}$ proteasome non-ATPase regulatory subunit 13 isoform 1 & 17 & 43 & 1.302 \\
\hline PSMB7 & proteasome subunit beta type- 7 precursor & 5 & 17 & 1.278 \\
\hline PSMD2 & $26 \mathrm{~S}$ proteasome non-ATPase regulatory subunit 2 isoform 1 & 31 & 74 & 1.257 \\
\hline PSMD14 & $26 \mathrm{~S}$ proteasome non-ATPase regulatory subunit 14 & 13 & 23 & 1.222 \\
\hline PSMC4 & $26 \mathrm{~S}$ protease regulatory subunit $6 \mathrm{~B}$ isoform 1 & 17 & 49 & 1.217 \\
\hline \multicolumn{5}{|c|}{ REPLICATE 4} \\
\hline PSMD9 & $26 \mathrm{~S}$ proteasome non-ATPase regulatory subunit 9 isoform 1 & 6 & 10 & 1.95 \\
\hline PSME2 & proteasome activator complex subunit 2 & 9 & 35 & 1.77 \\
\hline PSMD8 & $26 \mathrm{~S}$ proteasome non-ATPase regulatory subunit 8 & 11 & 22 & 1.579 \\
\hline PSMD4 & $26 \mathrm{~S}$ proteasome non-ATPase regulatory subunit 4 & 12 & 26 & 1.489 \\
\hline PSMD7 & $26 \mathrm{~S}$ proteasome non-ATPase regulatory subunit 7 & 11 & 23 & 1.411 \\
\hline PSMC4 & $26 \mathrm{~S}$ protease regulatory subunit $6 \mathrm{~B}$ isoform 1 & 23 & 70 & 1.382 \\
\hline
\end{tabular}

Columns from the right represent the gene symbol, protein description, ${ }_{-}$- number of unique peptides identified, number of peptide score matches (PSMs) and the fold change of the proteins in RR w.r.t P. 
Tumour formation was monitored by bioluminescence. As expected at day 14 post injection parent and RR cells treated with vehicle control or bortezomib showed almost similar growth, however, by day 33 while the parent cells treated with bortezomib had formed large tumours, the RR cells treated with bortezomib showed significant reduced bioluminescence intensity (Figure 6A, right panel). Presence of tumour cells was seen with Haematoxylin and Eosin staining in the brain slices of all the treatment groups of mice except for the brain tissue of mice treated injected with RR cells + bortezomib (Figure 6B). As represented in Figure 6D, the mice injected with bortezomib treated RR cells showed a significant decline in bioluminescence as compared to the group injected with bortezomib treated P cells. Also, the overall survival of this group (RR-BTZ) was significantly higher than that of the other three groups as shown in Figure 6E. Median survival of each group are as follows: P- VC-36 days, P-BTZ38 days, RR-VC-30 days, RR-BTZ-58 days. Further, we did intracranial injection of parental cells followed by radio therapy (fractionated dose of $14 \mathrm{~Gy}$ ) followed by intraperitoneal injection of bortezomib $(0.5 \mathrm{mg} / \mathrm{Kg}$ twice in a week for two weeks) as depicted in Figure $6 \mathrm{~F}$. Representative bioluminescence images from each group are shown in Figure 6G. The results show a significant reduction in bioluminescence of animals treated with radiation along with $\mathrm{BTZ}$ as compared to the radiation alone group (Figure $6 \mathrm{H}$ ). The disease free survival of mice was significantly higher in the group treated with radiation and BTZ as compared to radiated alone group (Figure 6I).

Together these data confirmed that the proteasome inhibition in vitro and in vivo resulted in tumour reduction and abrogation of relapse.
A

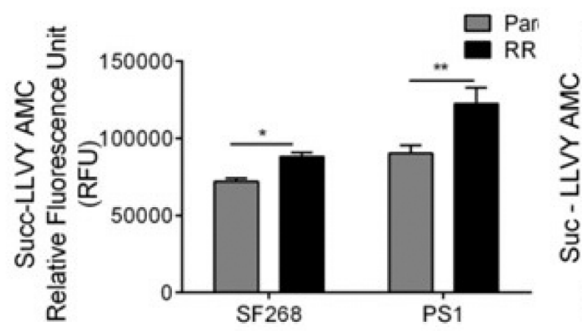

B

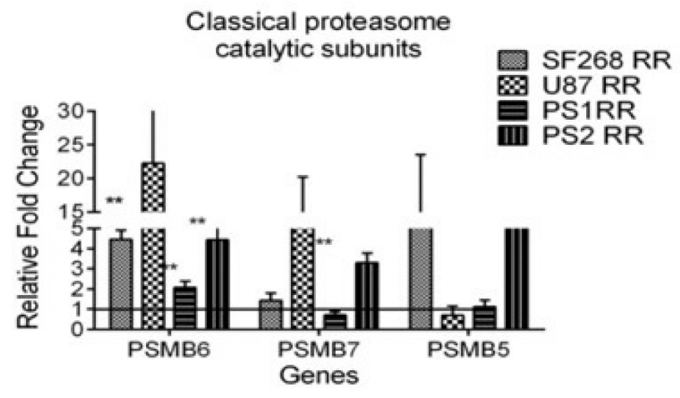

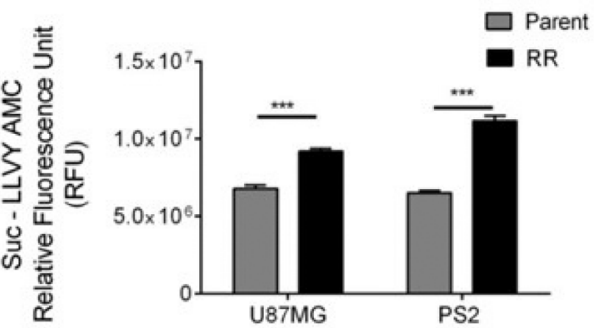

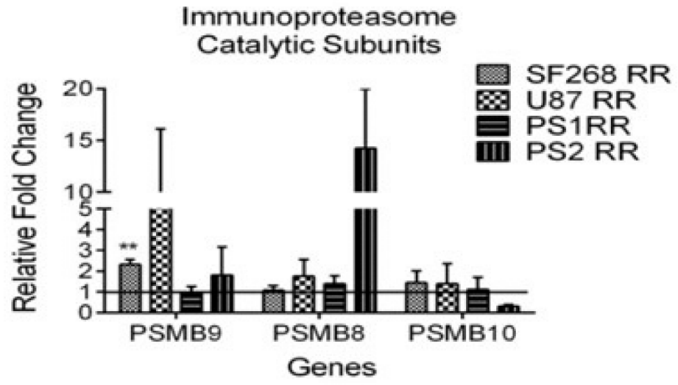

C

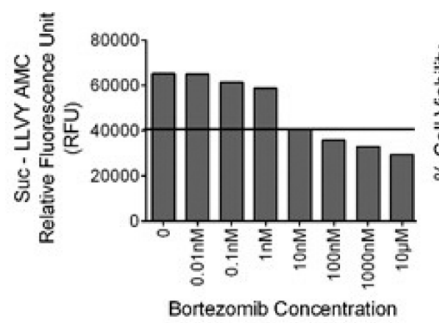

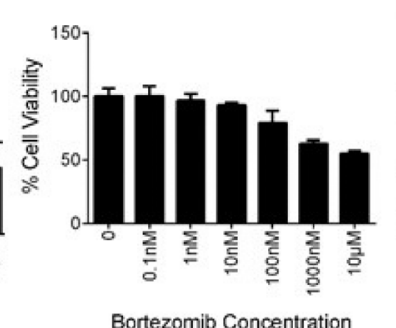

Bortezomib Concentration
D
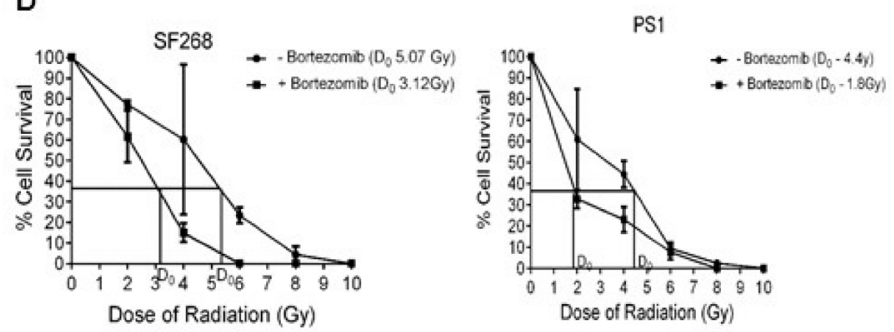

Figure 4: RR cells display enhanced proteasome activity and survival dependency on proteasomes in vitro. (A) Data represents the chymotrypsin like proteasome activity measured using Succ-LLVY AMC florigenic substrate in the P and RR population of SF268, U87MG, PS1 and PS2. (B) The graph depicts the RPL19 normalised mRNA levels of classical and Immunoproteasome proteasome beta catalytic subunits respectively in the RR population of SF268, U87MG, PS1, and PS2 compared to the parent population. (C) Proteasome activity inhibition and \% cell viability at different concentrations of proteasome inhibitor-Bortezomib in SF268. (D) Graph shows percentage of cells of SF268 and PS1 surviving at different doses of $\gamma$ radiation with and without $10 \mathrm{nM}$ Bortezomib in a clonogenic assay. (D) Bar graph represents the percentage of viable cells (at $72 \mathrm{hrs}$ ) as assessed by MTT assay at different concentrations of Bortezomib. Cells were treated with Bortezomib for $12 \mathrm{hrs}$. Results in each bar graph are the composite data from three independent experiments performed in triplicate (mean $\left.\pm \mathrm{SEM}) ;{ }^{* * *} P=0.001 \mathrm{c}\right)$ 


\section{DISCUSSION}

Radio resistance and recurrence is currently an inevitable consequence in the field of glioblastoma. Until now, the mechanisms of radio resistance in glioblastoma have been explored in in vitro and in in vivo settings either immediately post radiation or after generation of repeated doses of radiation (acquired resistance) but not in the residual radiation resistant cells. However, in this study we focused on the processes deregulated in the innately radiation resistant residual (RR) population as we have previously shown that these are the cells responsible for relapse in glioblastoma [9]. We performed iTRAQ based quantitative proteomic analysis on the parent $(\mathrm{P})$, innately radiation resistant residual (RR) and relapse (R) population. Amongst the many pathways, we found the proteasome pathway to be most significantly deregulated in the RR cells.

Proteasomes are well known targets in cancer therapy owing to their role in maintaining homeostasis of proteins involved in cell cycle, signalling pathways regulating cell survival and apoptosis [31-34]. Cancer cells harbour enhanced proteasome activity compared to their normal counterparts but the exact reason for this surge is still unknown. It is speculated that this escalation in proteasome activity is to cope with crisis such as
A

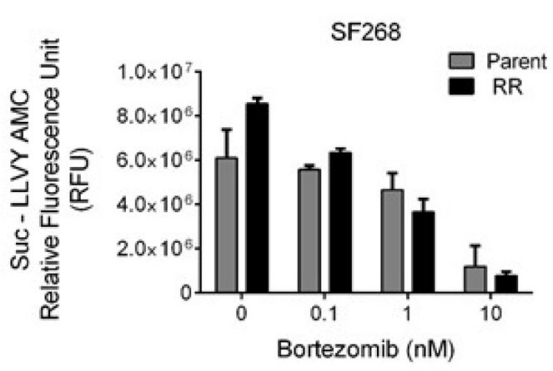

B

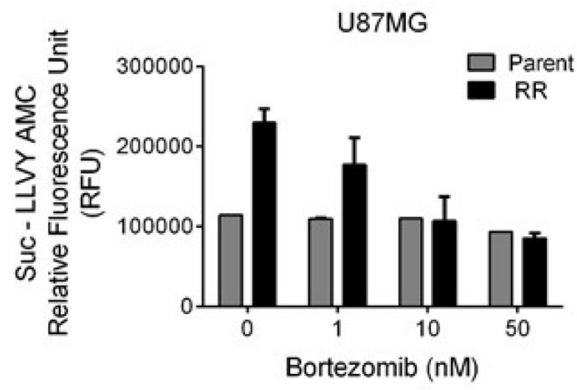

C

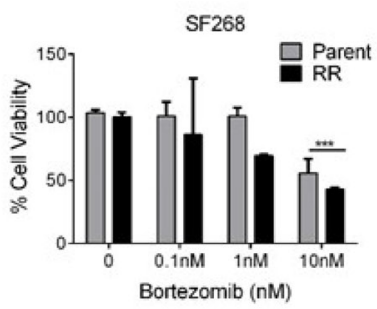

D

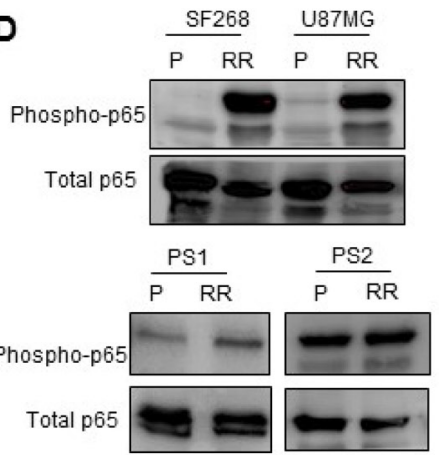

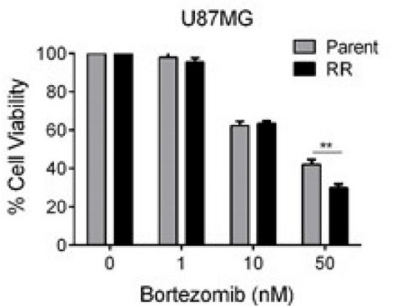

E

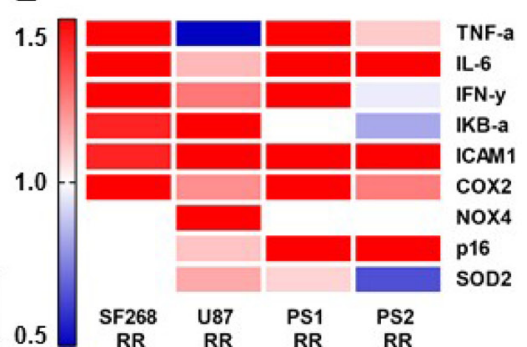

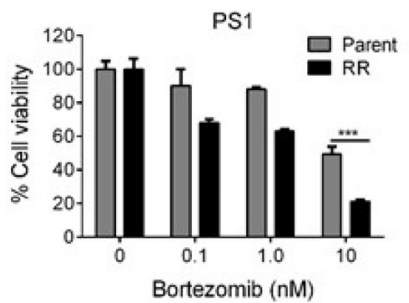
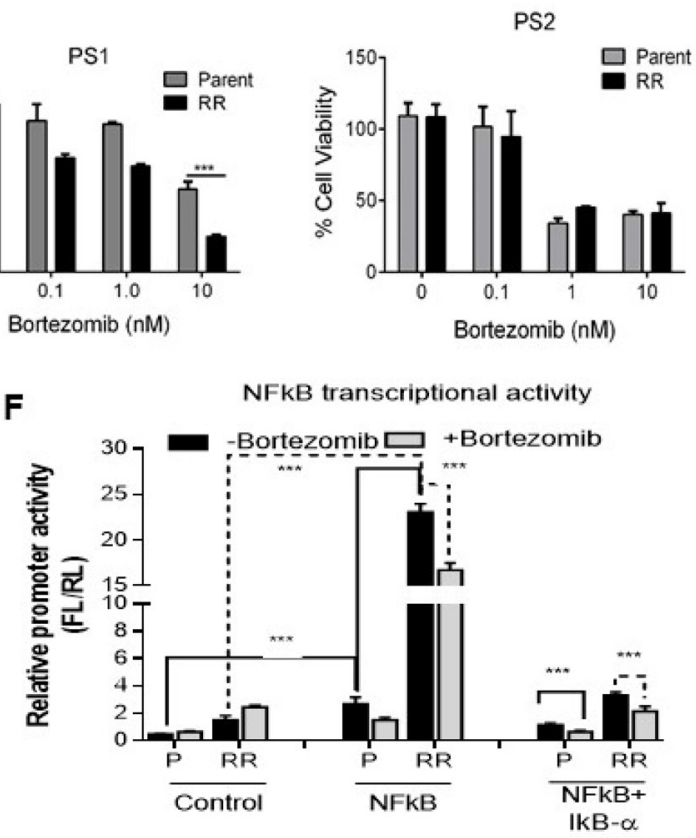

$\mathbf{F}$

Figure 5: Proteasomes indirectly regulate RR cell survival via the NFkB activation. (A and B) Bar graph shows proteasome activity in parent and RR cells of SF268 and U87 at different concentrations of the Bortezomib as mentioned. (C) Bar graph represents the percentage of viable cells (at $72 \mathrm{hrs)}$ as assessed by MTT assay at different concentrations of Bortezomib. Cells were treated with Bortezomib for 12 hrs. Results in each bar graph are the composite data from three independent experiments performed in triplicate ((mean $\left.\pm \mathrm{SEM}) ;{ }^{* * *} P=0.001\right)(\mathbf{D})$ Western blot represents the expression of phosphor- 65 in the $\mathrm{P}$ (Parent) and RR (Radiation resistant) cells of SF268, and U87MG, PS1 and PS2. Total (T) total- p65 levels were used as loading controls. (E) Heat map representation of gene expression values NFkB target genes by qPCR in the RR population of SF268, U87, PS1 and PS2 compared to the parent population. GAPDH was used as internal control. Results are the composite data from three independent experiments performed in triplicate (mean \pm SEM); ${ }^{*} P=0.05,{ }^{* *} P=0.01$ and ${ }^{* * *} P=0.001(\mathbf{F})$ Bortezomib treatment repressed the transcriptional activity of NFkB promoter luciferase constructs. The NFkB firefly luciferase construct was transfected into Parent and RR cells and then treated with Bortezomib as indicated. As a control Con A control plasmid was transfected with Renilla luciferase construct. The pTRIPZ IkB-alpha construct was used as NFkB suppressor. Luciferase values subsequent to normalization were plotted. 
mutational events and chromosomal instabilities. Although proteasomes are identified as direct targets of radiation, their inhibition is short lived and thus the need for drugs targeting their enzymatic activity [28, 35, 36]. Lower proteasome activity is shown to be a marker for tumour initiating cells and stem cells [37]. Proteasomes are also found to be downregulated in radio-resistant cells of breast cancer and prostate cancer established in vitro $[27,35,38]$. Contrary to these reports, we observed an enhanced expression and activity of proteasomes in the innate radioresistant residual cells of glioblastoma. Subsequently, we also identified 14 out of 431 downregulated proteins that harbour ubiquitin binding lysine residues (Supplementary Figure 1). These proteins in the RR cells, we predict to be either ubiquitin adapters or direct targets of the ubiquitin mediated proteasome machinery. This reduced number of proteins with ubiquitin binding attributes to the fact that proteasomes degrade a significant cellular portion by a ubiquitin independent manner also which is still incompletely understood [39].

Bortezomib preferentially inhibits the chymotrypsin like activity of proteasomes and is currently being
A
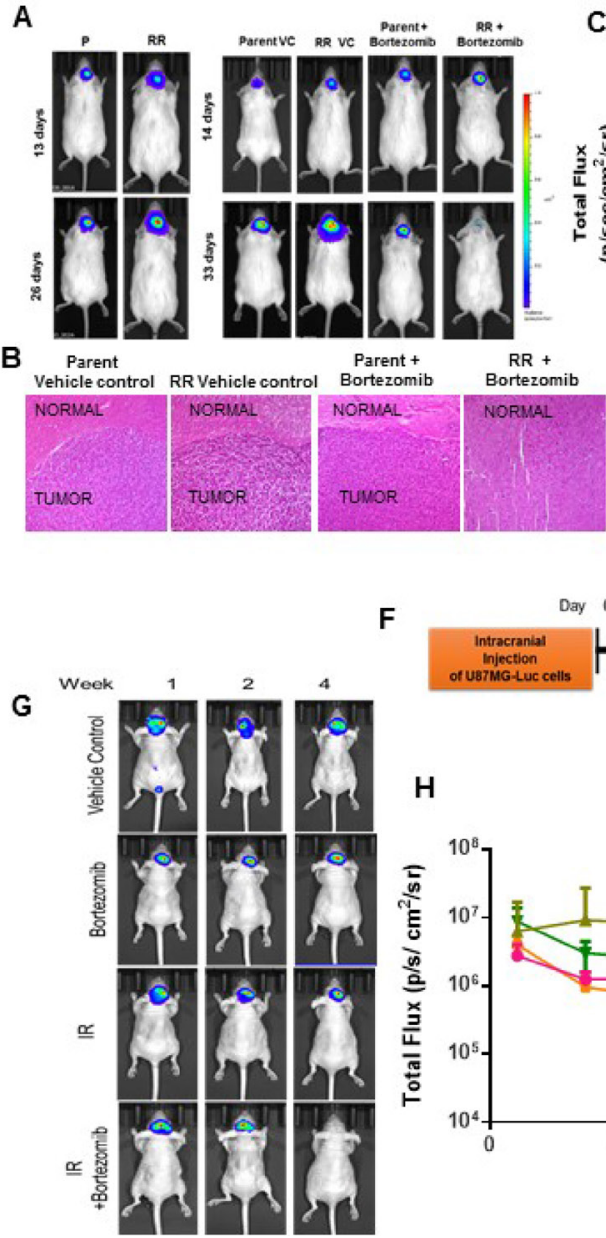

C

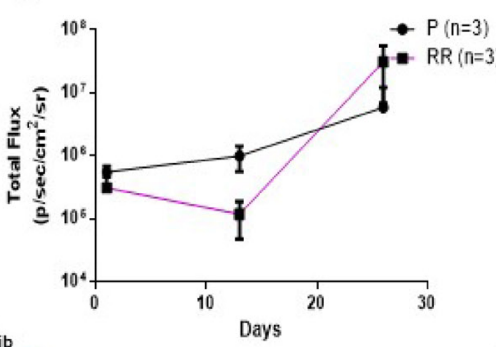

E

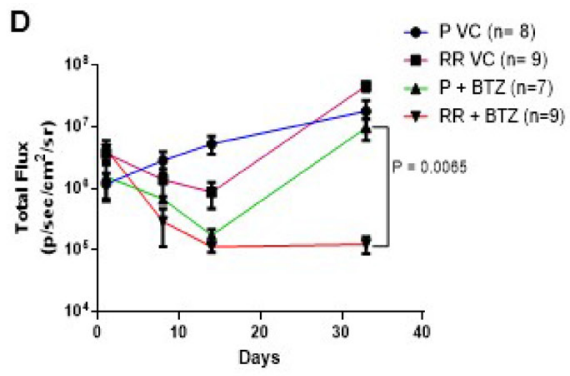

E Overall Survival

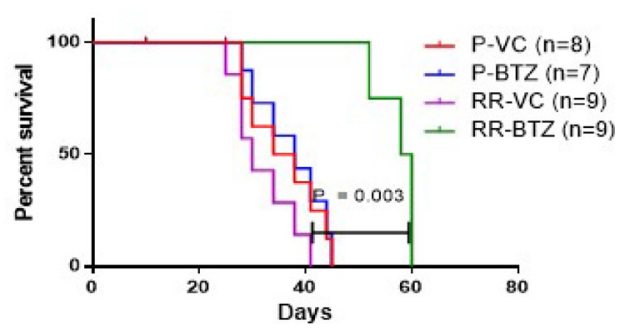

I

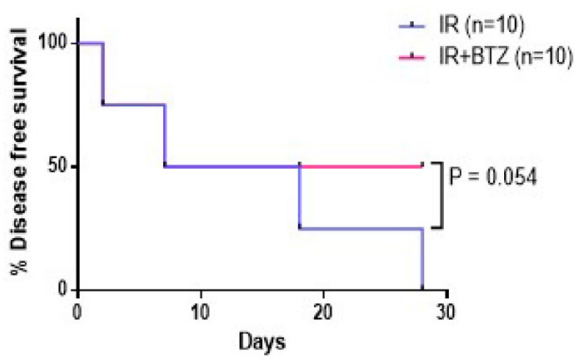

Figure 6: Proteasome inhibition reduces the tumorigenic potential of the cells in vivo. (A) Left panel - Representative bioluminescence images after orthotopic injection of U87MG-Luciferase labelled Parent (P) and Radiation Resistant (RR) cells. Right Panel - Bioluminescent images after orthotopic injection of U87MG-Luciferase labelled Parent (P) and Radiation Resistant (RR) cells treated with Vehicle Control (VC) and Bortezomib. (B) Hematoxylin and eosin (H\&E) staining of mice brain slices. Brain slices of the brain tissue from mice injected with Parent Vehicle control, RR Vehicle Control, Parent + Bortezomib, RR + Bortezomib cells were formalin fixed and paraffin embedded. Sections stained with H\&E show regions infiltrated with tumour cells. All photomicrographs are shown with the same magnification. Bar $=100 \mu \mathrm{m}$. (C) Graph represents bioluminescence signal at different days post injection in mice injected with P and RR cells. (D) Graph represents bioluminescence intensity at different days post injection of mice injected with P and RR cells pretreated with bortezomib as compared to P and RR cells treated with vehicle control. ' $n$ ' represents number of mice per group. (E) Kaplein Meier Curve for the overall survival of the mice in the pretreated study. (F) Schematic representation for studying the effect of intraperitoneal injections of bortezomib along with radiation treatment of mice intracranially injected with parent GBM cells. IR-Radiation; BTZ-Bortezomib. (G) Representative bioluminescence images of tumor formation in the mice treated with IR and BTZ compared to the mice which were administered with Vehicle Control (VC), only BTZ and only IR. (H) Graphical representation of bioluminescence intensity recorded for mice treated with IR and BTZ compared to the mice which were administered only saline as Vehicle Control (VC), only BTZ, only IR. (I) Kaplein Meier Curve for \% tumor free animals in the radiation and intraperitoneally administered BTZ study. 
used in the treatment for multiple myeloma [28, 40, 41]. In GBM, it has been reported to sensitize the parent GBM cells to temozolomide and radiation treatment but after immediate exposure to the drug and radiation [42]. However, in our study we show that the residual resistant cells that are formed after a period of 5-7 days post radiation are more sensitive to proteasome inhibition compared to the parent cells, although, there is a differential response to proteasome inhibition amongst the cell lines (SF268, U87MG) and patient samples (PS1 \& PS2) as depicted in Figure 5C. This could be due to the heterogeneity of GBM tumours. The subtle effect of bortezomib seen in vitro after $72 \mathrm{hrs}$ post treatment is significantly enhanced in reducing tumorigenicity of the treated cells in vivo, suggesting a slow and prolonged effect of proteasome inhibition on the survival of the cells. A significant effect of proteasome inhibition was observed on the overall survival of mice which were injected with pre-treated RR-BTZ cells along with an increased $\%$ of tumour free mice when BTZ was administered intraperitoneally along with radiation as shown in Figure $6 \mathrm{H}$ and 6I. The increased levels of activated NFkB and its transcriptional activity in the RR cells correlate with previous reports where NFkB has been shown to promote radio resistance in Glioblastoma and other cancers. It has been reported to trigger pro-survival and anti-apoptotic signals by transcriptional activation of over 200 genes including the pro inflammatory cytokines, cell-cell adhesion molecules. We have observed cytokines such as TNF- $\alpha$, IFN- $\gamma$, IL- 6 and antioxidant genes such COX2 levels increased in the RR. Its activation can occur via IkB- $\alpha$ degradation (Classical pathway) or the by TNF- $\alpha$ (alternative pathway) [43-45]. However, the exact mechanism downstream to higher proteasome expression and NFkB activity in the RR cells needs to be further explored. Nonetheless, this study as illustrated in Figure 7, establishes that proteasomes aid the survival of the innate radiation resistant population via NFkB pathway and hence can be valuable targets for precluding relapse in glioblastoma.

\section{MATERIALS AND METHODS}

\section{Cell culture and drug treatment}

GBM grade IV cell lines U87MG and SF268 were obtained from ATCC in 2011. These cell lines were last authenticated in the laboratory by short tandem repeat profiling based on eight markers in May 2014. The cell line was maintained in DMEM containing $10 \%(\mathrm{v} / \mathrm{v})$ FBS, penicillin $(200 \mathrm{U} / \mathrm{ml})$, streptomycin $(100 \mu \mathrm{g} / \mathrm{ml})$ and incubated at $37^{\circ} \mathrm{C}$ in a humidified incubator with an atmosphere of $50 \mathrm{~mL} / \mathrm{L} \mathrm{CO}_{2}$. Proteasome inhibitor was obtained from NATCO.

\section{Cell synchronization and radiation treatment}

The cells growing in 10\% FBS containing media were washed with $1 \mathrm{X}$ PBS. The cells were incubated with $0.05 \%$ FBS containing DMEM for 72 hrs. After 72 hrs, cells were replaced by $10 \%$ FBS containing median and were irradiated using $60 \mathrm{Co} \gamma$-rays at the respective lethal dose.

\section{Protein extraction}

10 million cells of the Parent (P), Radiation Resistant (RR) and Relapse (R) cells were grown under normal growth conditions. The media was aspirated and the cells were washed thrice with cold 1 X PBS after which the cells were scraped and pelleted down. The cell pellet was suspended in $150 \mu \mathrm{l}$ of $0.5 \%$ SDS Solution and sonicated with 10 pulses each for 10 secs. The sonicated cells were centrifuged at 4000 RPM for 15 mins at $4^{\circ} \mathrm{C}$ and the supernatant was used for the proteomic analysis. The protein concentration was determined using bichoninic acid assay and equal amounts of protein from the 3 conditions were taken for further analysis.

\section{iTRAQ labelling}

Protein extracts from the untreated, radiation resistant and relapse cells were digested with trypsin and

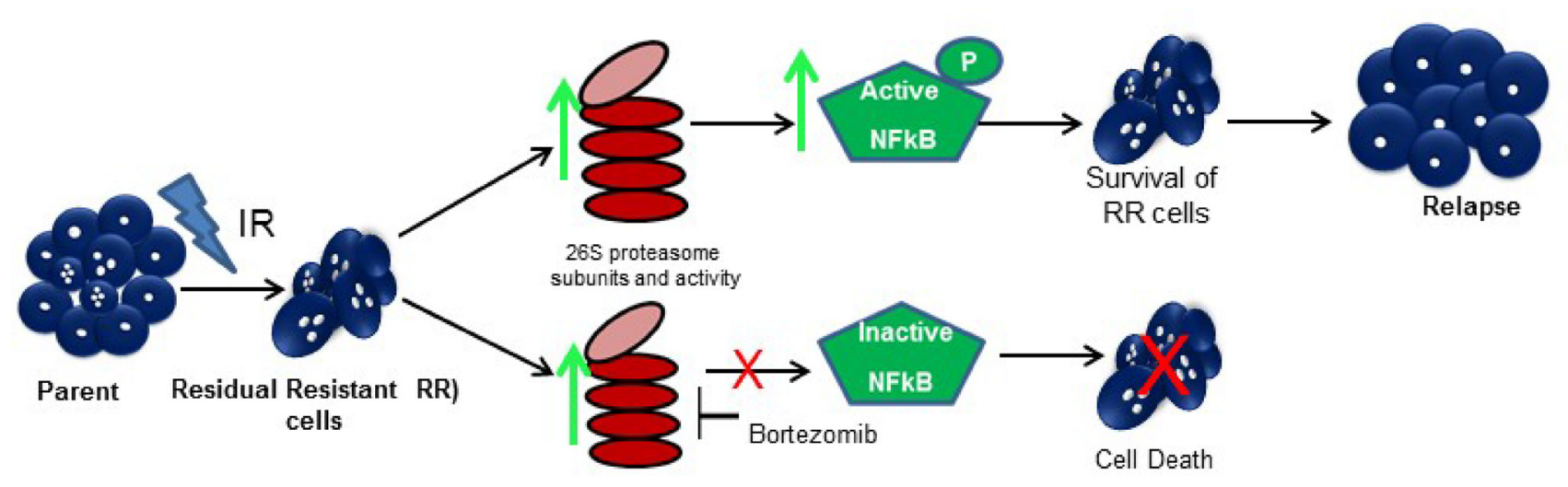

Figure 7: Proposed model for the study. 
the peptides were labelled with iTRAQ reagents according to the manufacturer's instructions (iTRAQ Reagents Multiplex kit; Applied Biosystems/MDS Sciex, Foster City, CA). Briefly, $80 \mu \mathrm{g}$ of protein from each sample was reduced, alkylated and digested with sequencing grade trypsin; (Promega, Madison, WI, USA). Peptides from $\mathrm{P}, \mathrm{RR}$ and $\mathrm{R}$ were labelled with iTRAQ reagents containing 114, 115 and 116 reporter ions, respectively. The three labelled samples were pooled, vacuum-dried and subjected to fractionation by strong cation exchange (SCX) chromatography.

\section{SCX fractionation}

The pooled sample after iTRAQ labelling was resuspended in $1 \mathrm{ml}$ of buffer A [10 mM KH2PO4, 25\% (v/v) acetonitrile (ACN), $\mathrm{pH} 2.9]$ and separated on a SCX column (Zorbax 300-SCX, $5 \mu \mathrm{m}, 2.1 \mathrm{~mm}$ ID $\times 50 \mathrm{~mm}$, Agilent Technologies, Santa Clara, CA, USA) at a flow rate of $700 \mu \mathrm{l} / \mathrm{min}$ with a $40 \mathrm{~min}$ gradient [ $5 \mathrm{~min}, 0-5 \%$ buffer B (buffer $\mathrm{A}+350 \mathrm{mM} \mathrm{KCl}$ ); $5 \mathrm{~min}, 5-10 \%$; $5 \mathrm{~min}, 10-23 \%$; $5 \mathrm{~min}, 23-50 \%$; $10 \mathrm{~min}, 50-100 \%$; $10 \mathrm{~min}, 100 \% \mathrm{~B}$ ]. One minute fractions were collected, vacuum-dried and desalted using C18 cartridge (Pierce, Rockford, USA) as per the manufacturer's instructions. After desalting, consecutive fractions were pooled to obtain a total of thirteen fractions for LC-MS/MS analysis.

\section{LC-MS/MS analysis}

Nanoflow electrospray ionization tandem mass spectrometric analysis of peptide samples was carried out using LTQ-Orbitrap Velos (Thermo Scientific, Bremen, Germany) interfaced with Agilent's 1200 Series nanoflow LC system. The chromatographic capillary columns used were packed with Magic C18 AQ (particle size $5 \mu \mathrm{m}$, pore size 100Å; Michrom Bioresources, Auburn, CA, USA) reversed phase material in $100 \% \mathrm{ACN}$ at a pressure of 1000 psi. The peptide sample from each SCX fraction was enriched using a trap column $(75 \mu \mathrm{m} \times 2 \mathrm{~cm})$ at a flow rate of $3 \mu \mathrm{l} / \mathrm{min}$ and separated on an analytical column $(75 \mu \mathrm{m} \times 10 \mathrm{~cm})$ at a flow rate of $350 \mathrm{nl} / \mathrm{min}$. The peptides were eluted using a linear gradient of $7-30 \%$ ACN over $65 \mathrm{~min}$. Mass spectrometric analysis was carried out in a data dependent manner with full scans acquired using the Orbitrap mass analyser at a mass resolution of 60,000 at $400 \mathrm{~m} / \mathrm{z}$. For each MS cycle, twenty most intense precursor ions from a survey scan were selected for MS/ MS and fragmentation detected at a mass resolution of 15,000 at $\mathrm{m} / \mathrm{z} 400$. The fragmentation was carried out using higher-energy collision dissociation (HCD) as the activation method with $40 \%$ normalized collision energy. The ions selected for fragmentation were excluded for $30 \mathrm{sec}$. The automatic gain control for full FT MS was set to 1 million ions and for FT MS/MS was set to 0.1 million ions with a maximum time of accumulation of $500 \mathrm{~ms}$, respectively. For accurate mass measurements, the lock mass option was enabled.

\section{Protein identification and quantitation}

The MS data was analyzed using Proteome Discoverer (Thermo Fisher Scientific, Version 1.4). The workflow consisted of a spectrum selector and a reporter ion quantifier. MS/MS search was carried out using SEQUEST and MASCOT search algorithms against the NCBI RefSeq database (release 52 40) containing 31,811 proteins. Search parameters included trypsin as the enzyme with 1 missed cleavage allowed; oxidation of methionine was set as a dynamic modification while alkylation at cysteine and iTRAQ modification at N-terminus of the peptide and lysine were set as static modifications. Precursor and fragment mass tolerance were set to 20 ppm and 0.1.Da, respectively. False Discovery Rate (FDR) was calculated by searching the proteomic data against a decoy protein database. Only those Peptide Spectrum Matches (PSMs) that qualified a 1\% FDR threshold were considered for further analysis. Unique peptide (s) for each protein identified was used to determine relative protein quantitation based on the relative intensities of reporter ions released during MS/MS fragmentation of peptides.

\section{Bioinformatics analysis}

Heat Map representation for the differential genes on the basis of their relative peptide intensities was constructed using MeV software (v 4.9.0). Unsupervised Hierarchical clustering of the genes was done using Pearson Correlation method. Functional annotation and Gene enrichment pathway analysis was done using Cytoscape (v 3.5.1) ClueGo (v 1.8) and CluPedia (v 1.0) plugin with default parameters. KEGG and REACTOME pathway databases were used for reference.

\section{Western blot analysis}

Cells were lysed using EBC lysis buffer (120 mM $\mathrm{NaCl}, 50$ mM Tris-Cl (pH 8.0), 0.5\% (v/v) Nonidet P-40, $50 \mu \mathrm{g} / \mathrm{ml}$ PMSF and protease, phosphatase inhibitor cocktail for 45 minutes on ice. The supernatant were collected and $40 \mathrm{ug}$ of protein was used for immunoblotting using anti-YBX3 (rabbit; 1:1000; Pierce), anti-PSMB4 (rabbit; 1:1000; Pierce), and anti-PSMD10 (rabbit; 1:1000; Pierce), Actin (Sigma; 1:4000 dilutions), was used as a loading control. Immune-reactive proteins were visualized using an enhanced chemiluminescence (ECL) reagent (Pierce).

\section{MTT cytotoxicity assay}

5000 cells/well were seeded in 96 well plates for overnight. Bortezomib (Bortenat $2 \mathrm{mg}$; Natco Company) was added at different concentration i.e. $0.1 \mathrm{nM}, 1 \mathrm{nM}$, $10 \mathrm{nM}$ and $100 \mathrm{nM}$. After $72 \mathrm{hrs} 10 \mu \mathrm{L}$ of MTT reagent 
(5 mg/ml in PBS, Himedia TC191-1G) was added to each well and incubated for $4 \mathrm{~h}$. Crystals were dissolved using freshly prepared acidified isopropanol containing $10 \%$ tritonX-100. Optical density was measured at $570 \mathrm{nM}$ by (SPECTROstar ${ }^{\mathrm{NANO}}$ star spectrophotometer).

\section{Proteasome activity assay}

0.1 million cells were pelleted, washed twice with 1X PBS and resuspended in ATP buffer containing $50 \mathrm{mM}$ Tris (pH 7.5), $5 \mathrm{mM} \mathrm{MgCl} 2,1 \mathrm{mMATP}, 10 \%$ glycerol and protease inhibitor cocktail (Sigma). Cell suspensions were ultra-sonicated for four cycles of $5 \mathrm{~s}$ each (with $1 \mathrm{~s}$ break after each $2 \mathrm{~s}$ ) at $30 \mathrm{kHz}$ on ice. Proteasome activity was measured using $50 \mu \mathrm{M}$ Suc-LLVY-7-amino-4-methyl coumarin substrate and fluorescence readings were taken at excitation $355 \mathrm{~nm} / \mathrm{emission} 460 \mathrm{~nm}$.

\section{Trypan blue exclusion assay}

0.1 million cells from all cultures were seeded in a 24 well plate and irradiated with the lethal dose of radiation. Viable cells from each well were counted every alternative day till 22 days to monitor the cell survival post radiation on a haemocytometer.

\section{Orthotopic xenograft mouse experiments}

All animal experiments were licensed through the Laboratory Animal Facility of ACTREC, TMC. Protocols were reviewed by the Institutional Animal Ethics Committee (IAEC). NUDE/SCID mice (6-8 weeks old) bred and maintained in an isolated facility within a specific pathogen-free environment were used for this study. $1 \times 10^{5}$ pLenti6-luc2 U87MG cells stably expressing luciferase were intracranially injected for generating the orthotopic GBM model and for studying the tumorigenicity of pre-treated Parent and RR cells. $2.5 \times 10^{5}$ pLenti6-luc2 U87MG stably expressing luciferase were intracranially injected for studying the effect of proteasome inhibitor along with radiation. In order to perform intracranial injection, the cells were suspended in $5 \mu 1 \mathrm{XX}$ PBS prior to injection and kept on ice until injected. Prior to injecting the cells intracranially, the mice were anesthetized using an injection mix of Ketamine $(120 \mathrm{mg} / \mathrm{kg}) /$ Xylazine $(\mathrm{mg} /$ $\mathrm{kg}$ )/Saline and the mice was placed on the stereotaxic for stereotactic surgery. A $10 \mathrm{~mm}$ to $15 \mathrm{~mm}$ long incision was made on top of the skull. A small hole was drilled using a sterile 26 gauge sharp needle at $1 \mathrm{~mm}$ posterior to bregma and $2 \mathrm{~mm}$ lateral to coronal suture and $2.5 \mathrm{~mm}$ depth. The $5 \mu 1$ cell suspension was then loaded onto the Hamilton syringe and injected at a rate of $1 \mu \mathrm{l}$ per minute for a total of 6-8 minutes. The tumours were allowed to grow and animals were sacrificed using $\mathrm{CO}_{2}$ at the onset of disease symptoms, such as weight and activity loss, and the brains were removed.

\section{Radiation and drug treatment of orthotopic GBM mouse model.}

The mice were divided into four groups post $7-10$ days of intracranial injection: Vehicle control, bortezomib (Bortenat $2 \mathrm{mg}$, NATCO company), Radiated group, Radiation and BTZ group. Radiation was delivered to the whole brain of anesthetized mice, immobilized in a plastic chamber using 60Co $\gamma$-rays. A total dose of $14 \mathrm{~Gy}$ was administered over a period of 7 days. $0.5 \mathrm{mg} / \mathrm{Kg}$ of bortezomib was administered intraperitoneally twice in a week for 2 weeks.

\section{Bioluminescence imaging of orthotopic tumor xenografts}

Mice were anaesthetized with Ketamine/Xylazine and were administered luciferin (D-Luciferin potassium salt, $150 \mathrm{mg} / \mathrm{kg}$, Calliper Life Sciences) via intraperitoneal injection. The images were acquired 10-12 minutes post injection. The time chosen was based on the pharmacokinetics of luciferin which defines that maximum luminescence emission and greatest sensitivity of detection will be obtained when cell luminescence is detected after 10-15 mins of injection of luciferin. The selected imaging time was maintained as constant among all the animals to be imaged. Regions of interest encompassing the intracranial area of signal were defined using Living Image software, and the total photons $/ \mathrm{s} / \mathrm{sr} / \mathrm{cm}^{2}$ (photons per second per steradian per square $\mathrm{cm}$ ) was recorded.

\section{Statistical methods}

All data are represented as means \pm standard error means (SEMs). The two-tailed Student's $t$-test was applied for statistical analysis. The Kaplan-Meier curve was plotted to generate the survival curves and to estimate the median survival values. Differences between survival curves were compared using a log-rank test.

\section{ACKNOWLEDGMENTS}

We thank Dr Neelam Shirsat and Dr Amit Dutt for providing the glioma cell lines. We acknowledge the funding from Department of Biotechnology (BT/PR4040/ MDE/30/792/2012) and Tata Memorial Centre to SD

\section{CONFLICTS OF INTEREST}

Authors declare no conflicts of interest.

\section{REFERENCES}

1. Stupp R, Mason WP, van den Bent MJ, Weller M, Fisher $\mathrm{B}$, Taphoorn MJ, Belanger K, Brandes AA, Marosi C, Bogdahn U, Curschmann J, Janzer RC, Ludwin SK, et al; 
and European Organisation for Research and Treatment of Cancer Brain Tumor and Radiotherapy Groups; and National Cancer Institute of Canada Clinical Trials Group. Radiotherapy plus Concomitant and Adjuvant Temozolomide for Glioblastoma. The new england journal of medicine. 2005.

2. Stupp R, Hegi ME, Mason WP, van den Bent MJ, Taphoorn MJ, Janzer RC, Ludwin SK, Allgeier A, Fisher B, Belanger K, Hau P, Brandes AA, Gijtenbeek J, et al; European Organisation for Research and Treatment of Cancer Brain Tumour and Radiation Oncology Groups; National Cancer Institute of Canada Clinical Trials Group. Effects of radiotherapy with concomitant and adjuvant temozolomide versus radiotherapy alone on survival in glioblastoma in a randomised phase III study: 5-year analysis of the EORTCNCIC trial. Lancet Oncol. 2009; 10:459-66.

3. Zhang X, Zhang W, Cao WD, Cheng G, Zhang YQ. Glioblastoma multiforme: molecular characterization and current treatment strategy (Review). Exp Ther Med. 2012; 3:9-14. Review https://doi.org/10.3892/etm.2011.367.

4. Reardon DA, Wen PY. Therapeutic advances in the treatment of glioblastoma: rationale and potential role of targeted agents. Oncologist. 2006; 11:152-64. https://doi. org/10.1634/theoncologist.11-2-152.

5. Glas M, Rath BH, Simon M, Reinartz R, Schramme A, Trageser D, Eisenreich R, Leinhaas A, Keller M, Schildhaus HU, Garbe S, Steinfarz B, Pietsch T, et al. Residual tumor cells are unique cellular targets in glioblastoma. Ann Neurol. 2010; 68:264-69.

6. Kelley K, Knisely J, Symons M, Ruggieri R. Radioresistance of Brain Tumors. Cancers. 2016; 8.

7. Weller M, Cloughesy T, Perry JR, Wick W. Standards of care for treatment of recurrent glioblastoma - are we there yet? Neuro-oncol. 2013; 15:4-27. https://doi.org/10.1093/ neuonc/nos273.

8. Roy S, Lahiri D, Maji T, Biswas J. Recurrent Glioblastoma: where we stand. South Asian J Cancer. 2015; 4:163-73. https://doi.org/10.4103/2278-330X.175953.

9. Kaur E, Rajendra J, Jadhav S, Shridhar E, Goda JS, Moiyadi A, Dutt S. Radiation-induced homotypic cell fusions of innately resistant glioblastoma cells mediate their sustained survival and recurrence. Carcinogenesis. 2015; 36:685-95. https://doi.org/10.1093/carcin/bgv050.

10. Pandey A, Mann M. Proteomics to study genes and genomes. Nature. 2000; 405:837-46. https://doi.org/10.1038/35015709.

11. Chumbalkar V, Sawaya R, Bogler O. Proteomics: the new frontier also for brain tumor research. Curr Probl Cancer. 2008; 32:143-54. https://doi.org/10.1016/j. currproblcancer.2008.02.005.

12. Lage H. Proteomics in cancer cell research: an analysis of therapy resistance. Pathol Res Pract. 2004; 200:105-17. https://doi.org/10.1016/j.prp.2004.02.003.

13. Larance M, Lamond AI. Multidimensional proteomics for cell biology. Nat Rev Mol Cell Biol. 2015; 16:269-80. https://doi.org/10.1038/nrm3970.
14. Kalinina J, Peng J, Ritchie JC, Van Meir EG. Proteomics of gliomas: initial biomarker discovery and evolution of technology. Neuro-oncol. 2011; 13:926-42. https://doi. org/10.1093/neuonc/nor078.

15. Kumar DM, Patil V, Ramachandran B, Nila MV, Dharmalingam K, Somasundaram K. Temozolomidemodulated glioma proteome: role of interleukin-1 receptorassociated kinase-4 (IRAK4) in chemosensitivity. Proteomics. 2013; 13:2113-24. https://doi.org/10.1002/pmic.201200261.

16. Vogel TW, Zhuang Z, Li J, Okamoto H, Furuta M, Lee YS, Zeng W, Oldfield EH, Vortmeyer AO, Weil RJ. Proteins and protein pattern differences between glioma cell lines and glioblastoma multiforme. Clin Cancer Res. 2005; 11:362432. https://doi.org/10.1158/1078-0432.CCR-04-2115.

17. Hill JJ, Moreno MJ, Lam JC, Haqqani AS, Kelly JF. Identification of secreted proteins regulated by cAMP in glioblastoma cells using glycopeptide capture and labelfree quantification. Proteomics. 2009; 9:535-49. https:// doi.org/10.1002/pmic.200800257.

18. Furuta M, Weil RJ, Vortmeyer AO, Huang S, Lei J, Huang TN, Lee YS, Bhowmick DA, Lubensky IA, Oldfield EH, Zhuang Z. Protein patterns and proteins that identify subtypes of glioblastoma multiforme. Oncogene. 2004; 23:6806-14. https://doi.org/10.1038/sj.onc.1207770.

19. Fang X, Wang C, Balgley BM, Zhao K, Wang W, He F, Weil RJ, Lee CS. Targeted tissue proteomic analysis of human astrocytomas. J Proteome Res. 2012; 11:3937-46. https://doi.org/10.1021/pr300303t.

20. Deighton RF, Le Bihan T, Martin SF, Barrios-Llerena ME, Gerth AM, Kerr LE, McCulloch J, Whittle IR. The proteomic response in glioblastoma in young patients. $\mathrm{J}$ Neurooncol. 2014; 119:79-89. https://doi.org/10.1007/ s11060-014-1474-6.

21. Com E, Clavreul A, Lagarrigue M, Michalak S, Menei P, Pineau C. Quantitative proteomic Isotope-Coded Protein Label (ICPL) analysis reveals alteration of several functional processes in the glioblastoma. J Proteomics. 2012; 75:3898913. https://doi.org/10.1016/j.jprot.2012.04.034.

22. Polisetty RV, Gautam P, Sharma R, Harsha HC, Nair SC, Gupta MK, Uppin MS, Challa S, Puligopu AK, Ankathi P, Purohit AK, Chandak GR, Pandey A, Sirdeshmukh R. LC-MS/MS analysis of differentially expressed glioblastoma membrane proteome reveals altered calcium signaling and other protein groups of regulatory functions. Mol Cell Proteomics. 2012; 11:M111.013565.

23. Collet B, Guitton N, Saïkali S, Avril T, Pineau C, Hamlat A, Mosser J, Quillien V. Differential analysis of glioblastoma multiforme proteome by a 2D-DIGE approach. Proteome Sci. 2011; 9:16. https://doi.org/10.1186/1477-5956-9-16.

24. Niclou SP, Fack F, Rajcevic U. Glioma proteomics: status and perspectives. J Proteomics. 2010; 73:1823-38. https:// doi.org/10.1016/j.jprot.2010.03.007.

25. Thirant C, Galan-Moya EM, Dubois LG, Pinte S, Chafey P, Broussard C, Varlet P, Devaux B, Soncin F, Gavard J, 
Junier MP, Chneiweiss H. Differential proteomic analysis of human glioblastoma and neural stem cells reveals HDGF as a novel angiogenic secreted factor. Stem Cells. 2012; 30:845-53. https://doi.org/10.1002/stem.1062.

26. de Aquino PF, Carvalho PC, Nogueira FC, da Fonseca CO, de Souza Silva JC, Carvalho Mda G, Domont GB, Zanchin NI, Fischer Jde S. A Time-Based and Intratumoral Proteomic Assessment of a Recurrent Glioblastoma Multiforme. Front Oncol. 2016; 6:183.

27. Della Donna L, Lagadec C, Pajonk F. Radioresistance of prostate cancer cells with low proteasome activity. Prostate. 2012; 72:868-74. https://doi.org/10.1002/pros.21489.

28. McBride WH, Iwamoto KS, Syljuasen R, Pervan M, Pajonk F. The role of the ubiquitin/proteasome system in cellular responses to radiation. Oncogene. 2003; 22:575573. https://doi.org/10.1038/sj.onc.1206676.

29. The UniProt Consortium. UniProt: the universal protein knowledgebase. Nucleic Acids Res. 2017; 45:D158-69. https://doi.org/10.1093/nar/gkw1099.

30. Monika A. Jarzabek PCH, Kai O. Skaftnesmo, Emmet McCormack, Patrick Dicker, Jochen H.M. Prehn, Rolf Bjerkvig, and Annette T. Byrne. In Vivo Bioluminescence Imaging Validation of a Human Biopsy-Derived Orthotopic Mouse Model of Glioblastoma Multiforme. Molecular Imaging. 2013.

31. Burger AM, Seth AK. The ubiquitin-mediated protein degradation pathway in cancer: therapeutic implications. Eur J Cancer. 2004; 40:2217-29. https://doi.org/10.1016/j. ejca.2004.07.006.

32. Qureshi N, Morrison DC, Reis J. Proteasome protease mediated regulation of cytokine induction and inflammation. Biochim Biophys Acta. 2012; 1823:2087-93. https://doi.org/10.1016/j.bbamcr.2012.06.016.

33. Livneh I, Cohen-Kaplan V, Cohen-Rosenzweig C, Avni N, Ciechanover A. The life cycle of the $26 \mathrm{~S}$ proteasome: from birth, through regulation and function, and onto its death. Cell Res. 2016; 26:869-85. https://doi.org/10.1038/cr.2016.86.

34. Pajonk F, van Ophoven A, Weissenberger C, McBride WH. The proteasome inhibitor MG-132 sensitizes PC-3 prostate cancer cells to ionizing radiation by a DNA-PKindependent mechanism. BMC Cancer. 2005; 5:76. https:// doi.org/10.1186/1471-2407-5-76.

35. Pervan M, Iwamoto KS, McBride WH. Proteasome structures affected by ionizing radiation. Mol Cancer Res. 2005; 3:381-90. https://doi.org/10.1158/1541-7786.MCR-05-0032.
36. Pajonk F, McBride WH. Ionizing radiation affects $26 \mathrm{~s}$ proteasome function and associated molecular responses, even at low doses. Radiother Oncol. 2001; 59:203-12. https://doi.org/10.1016/S0167-8140(01)00311-5.

37. Tamari K, Hayashi K, Ishii H, Kano Y, Konno M, Kawamoto K, Nishida N, Koseki J, Fukusumi T, Hasegawa S, Ogawa H, Hamabe A, Miyo M, et al. Identification of chemoradiation-resistant osteosarcoma stem cells using an imaging system for proteasome activity. Int J Oncol. 2014; 45:2349-54. https://doi.org/10.3892/ijo.2014.2671.

38. Smith L, Qutob O, Watson MB, Beavis AW, Potts D, Welham KJ, Garimella V, Lind MJ, Drew PJ, Cawkwell L. Proteomic identification of putative biomarkers of radiotherapy resistance: a possible role for the $26 \mathrm{~S}$ proteasome? Neoplasia. 2009; 11:1194-207. https://doi. org/10.1593/neo.09902.

39. Baugh JM, Viktorova EG, Pilipenko EV. Proteasomes can degrade a significant proportion of cellular proteins independent of ubiquitination. J Mol Biol. 2009; 386:81427. https://doi.org/10.1016/j.jmb.2008.12.081.

40. Crawford LJ, Walker B, Irvine AE. Proteasome inhibitors in cancer therapy. J Cell Commun Signal. 2011; 5:101-10. https://doi.org/10.1007/s12079-011-0121-7.

41. Teicher BA, Tomaszewski JE. Proteasome inhibitors. Biochem Pharmacol. 2015; 96:1-9. https://doi. org/10.1016/j.bcp.2015.04.008.

42. Thaker NG, Zhang F, McDonald PR, Shun TY, Lewen MD, Pollack IF, Lazo JS. Identification of survival genes in human glioblastoma cells by small interfering RNA screening. Mol Pharmacol. 2009; 76:1246-55. https://doi. org/10.1124/mol.109.058024.

43. Cahill KE, Morshed RA, Yamini B. Nuclear factor- $\kappa B$ in glioblastoma: insights into regulators and targeted therapy. Neuro-oncol. 2016; 18:329-39. https://doi.org/10.1093/ neuonc/nov265.

44. Ahmed KM, Li JJ. NF-kappa B-mediated adaptive resistance to ionizing radiation. Free Radic Biol Med. 2008; 44:1-13. https://doi.org/10.1016/j.freeradbiomed.2007.09.022.

45. Pahl HL. Activators and target genes of Rel/NF-kappaB transcription factors. Oncogene. 1999; 18:6853-66. https:// doi.org/10.1038/sj.onc.1203239. 